\title{
Las distopías en las series de televisión contemporáneas:
}

una aproximación

Francisco Giménez Mateu

al362643@uji.es 
En las páginas que siguen me propongo presentar el proyecto preparado para el desarrollo de mi tesis doctoral enmarcada en el programa de doctorado en Estudios Interdisciplinares de Género. Una tesis doctoral que se centrará en el concepto filosófico de distopía a través de un análisis tanto literario como audiovisual de las ideas de utopía y distopía a lo largo de la historia. Para ello, estudiaré desde la utópica La República, de Platón, hasta la distópica 1984, de George Orwell; y desde la película Metrópolis, de Fritz Lang, hasta la serie de televisión El cuento de la criada, creada por Bruce Miller. En este artículo planteo una introducción a dicha tesis doctoral, además de un acercamiento a su metodología y objetivos propuestos: encontrar esos puntos comunes entre las producciones utópicas y distópicas analizadas que nos conduzcan a componer una noción integral de distopía para tratar de com-prender una definición de dicho término y des-cubrir si las relaciones de género, entre otras cosas, pueden definir aquel tipo de sociedades que damos en llamar distópicas. Por eso, como el texto siguiente se trata de una proyección, el lector puede echar en falta apartados tales como «Resultados» o "Conclusiones». Esto es así porque la finalidad de las próximas líneas es tan solo esbozar un proyecto que irá cogiendo forma en un futuro cercano y que, espero, poder describir en próximos números de Fòrum de Recerca.

Palabras clave: distopía, utopía, estudios de género, series de televisión, análisis literario, análisis audiovisual

\section{Introducción}

El espíritu de la distopía, siempre pesimista, se ha generalizado tanto en nuestro tiempo como en su momento lo hizo el espíritu, siempre optimista, de la utopía (Núñez Ladevéze, 1986: 122). Si podemos decir que la utopía aparece ligada a momentos históricos determinados, a momentos de crisis (Servier, 1969: 228), lo mismo podemos decir, pienso, de la distopía. Una distopía y utopía que quedan ligadas, también, en su definición. Porque si intentar definir la idea de utopía es, o puede ser, tanto o más inútil que definir el significado de filosofía (Blanco Martínez, 2000: 11), lo mismo podemos decir de la distopía. Y es que no fue hasta 2014 cuando José María Merino preparó este término para su entrada en el Diccionario de la Lengua Española (Morán Bueno, 2014; Costa Vila, 2014) y la definió así: «representación ficticia de una sociedad futura de características negativas causantes de alienación humana» (DLE 2014, 814). 
La primera referencia de la palabra utopía, la encontramos (con

todas sus ambigüedades) en Tomás Moro (Mumford, 2013: 9), en su libro De optimo reipublicae statu deque nova insula Utopía, publicado en 1516 (Trousson, 2011: 10). Y la primera referencia de la palabra distopía, la encontramos (aunque no significa exactamente lo que hoy entendemos por la palabra) en John Stuart Mill, en un discurso parlamentario en 1868: "It is, perhaps, too complimentary to call them utopians, they ought rather to be called dys-topians [...]» (Aldridge, 1984: 8). Con esto quería llegar a interpretar tanto a la utopía como a la distopía como elementos ligados a su propio tiempo, un tiempo que identifico con la modernidad y con la posmodernidad.

Aunque mitos hay en todos los pueblos del mundo, "utopías» (y añado, por lo tanto, "distopías») solo se han forjado en Occidente, debido, sobre todo, a esa concepción judeocristiana del mundo que contrapone lo que es a lo que debe (o debería) ser: ese sentimiento profundo de una meta por alcanzar (Cappelletti, 1966: 3; Servier, 1969: 230), ese deseo del "deber ser», ese afán por lo justo del que habla Martin Buber (1955: 17). Es, pues, esa idea de que hay un deber ser implícito en el ser mismo y que, además, puede explicitarse especulativamente, lo que introduce el rasgo utópico en el pensamiento (Núñez Ladevéze, 1986: 111). Jean Servier (1969: 230) describe dos grandes características de toda utopía: la descripción de una ciudad considerada perfecta y una crítica del orden social. Una crítica que, mediante la comparación con la realidad, muestra sus defectos (Núñez Ladevéze, 1986: 112). De ahí la definición que hace de utopía Martin Buber (1955: 17): «una expresión de algo que no existe, que solo es imaginario». Una expresión que, como ya he dicho, supone una crítica al presente y un intento de descubrir otras alternativas (Mumford, 2013: 10-11; Núñez Ladevéze, 1986: 114). Una actitud crítica que aparece ante el disgusto del modo de ser actual del mundo: un disgusto que nos prepara para comprender lo que este mundo tiene de equivocado (Buber, 1955: 18).

Si la modernidad, ya agotada, ha dejado paso a la posmodernidad (Díaz, 1999: 13, 31), lo mismo puede decirse, creo, de la utopía y la distopía: la utopía, ya agotada, ha dejado paso a la distopía. Una utopía que, relacionada en la modernidad con la dialéctica histórica, parecía justificar y legitimar cualquier presente (Devueau, 1961: 31-32). Además, como apunta Lewis Mumford (2013: 12-14): la gran mayoría de las utopías clásicas tienen en su base elementos cerrados, inflexibles y totalitarios. De ahí las debilidades esenciales de la utopía que, pienso, son superadas, ahora, con la distopía. Luis Núñez Ladevéze (1986: 120) afirma, en este sentido, que "el desencanto ha sustituido al candor de la utopía primigenia». Y Jean Servier (1969: 230) que «semejante angustia es a 
menudo generadora de sueños compensadores». Así pues, esa sensación de desánimo, pesimismo y desencanto desemboca en la distopía ( $y$, también, creo, en la posmodernidad): un instrumento poderoso con el que poder exponer el disentimiento, la protesta y el temor (Núñez Ladevéze, 1986: 121).

\section{Objetivos}

Como pienso que no pueden, a priori, separarse los conceptos de utopía y distopía para estudiarlos, he considerado totalmente necesario un acercamiento al concepto de distopía a través del de utopía. Por ello, mi entrada al mundo de la distopía se llevará a cabo a partir del de la utopía. Y para abrir las puertas de ese mundo utópico, tomaré las llaves de aquellas obras que se han considerado como fundantes del género utópico, como Utopía, de Tomás Moro (quien, dicho sea de paso, inventa el neologismo utopía); Ciudad del Sol, de Tommaso Campanella, o Nueva Atlántida, de Francis Bacon. También pasaré revista al contexto histórico que acompaña a estas obras porque toda obra nace en un tiempo, y tiempo y obra, pienso, no pueden leerse por separado. Luego de haber hecho una lectura literaria e histórica de la utopía, estaré preparado para entrar en el reino de la distopia. Una distopía (tema central de mi tesis doctoral) que, también, como la utopía, nace en un determinado tiempo. Por eso, haré el acercamiento a la distopía desde dos perspectivas. Uno, una perspectiva literaria (analizando cómo se pasa de un pensamiento utópico y optimista a un pensamiento distópico de corte pesimista) comparando la literatura utópica con la literatura distópica y descubriendo cómo, necesariamente, las obras utópicas (debido a sus limitaciones) nos conducen a las obras distópicas. Dos, una perspectiva audiovisual, analizando películas y series de televisión distópicas, porque si la distopía forma parte de un tiempo concreto (como defiendo) ese tiempo es el tiempo del cine, el tiempo de las series de televisión. Necesariamente, pues, haré un repaso de las primeras películas con una temática distópica clara, como puede ser, por ejemplo, Metrópolis, de Fritz Lang, en 1929, para observar cómo se pueden complementar la literatura y lo audiovisual para llevarnos de la mano a una noción de la distopía más precisa.

A continuación, entraré de lleno en la parte más específica de toda mi tesis doctoral: un análisis audiovisual de algunas series de televisión contemporáneas para desembocar en cómo se nos muestra, qué mecanismos utiliza y por qué nos afecta emocionalmente el contenido audiovisual de dichas series de televisión. Me gustaría comentar que la elección de estas no es arbitraria y que se fundamenta en un objetivo claro: descubrir cómo nos pueden acercar las series de televisión a un contenido 
existencial, a valores morales y a conceptos filosóficos. Además, para dotar a todo este estudio de una perspectiva de género, dicha elección se meditará y mucho. De ahí que pueda anticipar, por ahora, El cuento de la criada, serie de televisión (además de obra literaria) que nos narra una sociedad donde la mujer ha quedado relegada a un segundo plano.

Con lo dicho, puedo preludiar que mi tesis doctoral contará con el siguiente objetivo general: analizar la idea de distopía en la actualidad a través de un estudio audiovisual de algunas series de televisión actuales como El cuento de la criada con el fin de descubrir esos elementos comunes que hacen que podamos llamarlas "distópicas» para des-velar, desde allí, una teoría y definición de la distopía. Además, también trabajaré estos otros objetivos específicos: primero, desarrollar una historia de la "utopía» a partir de sus textos más significativos para encontrar esos elementos comunes que hacen que se las pueda llamar "utopías» e imaginar una definición o una teoría que pudiera incluirlas a todas. Segundo, estudiar una historia de la «distopía» a través de un análisis tanto de sus aportes literarios como de sus producciones audiovisuales más significativas para encontrar, igual que en el caso anterior, esos elementos comunes que hacen que se las pueda llamar "distopías» e imaginar una definición o una teoría que pudiera incluirlas a todas. Tercero, encontrar una identificación histórica tanto de la utopía como de la distopía para comprender por qué aparecen en un determinado momento y no en otro y relacionarlas, así, con su tiempo y entre ellas mismas. Y cuarto, llevar a cabo un análisis literario de todas las obras utópicas y distópicas citadas, ademá, de complementarlo con un análisis audiovisual de algunas de sus producciones audiovisuales (en este caso, algunas series de televisión) para entender cómo se vierten las ideas literarias en el mundo audiovisual, cómo se complementan y cómo pueden ayudarnos a entender algunos conceptos (en este caso, la distopía) de una forma más completa.

\section{Metodología}

Con lo ya anticipado, queda claro que para estudiar el concepto de distopía, será necesario, a su vez, estudiar el concepto de «utopía». Como ya he dicho, entiendo la distopía como un cambio histórico inevitable que nos lleva a movernos desde la utopía hasta la distopía. Por eso, mi investigación acerca de la distopía arrancará necesariamente con una aproximación a la utopía para, una vez formada una idea de qué es, poder movernos hasta la distopía.

Para rastrear la utopía me centraré, primero, en obras filosóficas, por ser estas su primera manifestación. Echaré mano, pues, tanto de obras clásicas que pueden considerarse utópicas 
(como La República, de Platón), pasando por otras obras que se considera que fundaron la utopía como género literario (como Utopía, de Tomás Moro; Ciudad del Sol, de Tommaso Campanella, o Nueva Atlántida, de Francis Bacon), hasta llegar al siglo xx (con obras como Altneuland, de Theodor Herzl, o Una utopía moderna, de H. G. Wells). No está de más decir que también analizaré el contexto en el que aparecen todas estas obras para entender por qué aparecen en ese momento y no en otro.

Una vez llevado a cabo este recorrido histórico y literario a través de la utopía, avanzaré hasta la distopía y sus manifestaciones. En este caso, para observar cómo se pasa del pensamiento utópico al pensamiento distópico, echaré mano de algunas obras que se han considerado fundantes de la distopía como género literario como Un mundo feliz, de Aldous Huxley; 1984, de George Orwell, o Fahrenheit 451 , de Ray Bradbury. Tras esto, también pasaré a revisar algunas otras obras distópicas para complementar la lectura de las anteriores como La fe de nuestros padres, de Philip K. Dick; La pianola, de Kurt Vonnegut, entre otras. Acompañaré Todos sobre Zanzíbar, de John Brunner, en este recorrido literario, al igual que en el caso anterior, de un estudio histórico, en el que observaré el tiempo en el que aparecen estas obras, para entender por qué aparecen entonces, en ese determinado momento y no en otro.

Y tras este prometedor análisis literario e histórico de los conceptos de utopía y distopía, y con una idea ya formada de qué es eso que hoy en día llamamos distopía, centraré mi análisis, ya específicamente, en cómo se muestra en las series de televisión (parte novedosa de mi tesis doctoral). Así pues, a través de un análisis audiovisual (cuya metodología desarrollaré a lo largo del trabajo), estudiaré tanto la estética de las series de televisión (a través de un análisis de su lenguaje y narrativa audiovisual) como la parte sociopolítica y ética (a través de un análisis de los componentes sociales, políticos y éticos inherentes a sus tramas y especialmente de las relaciones de género), de modo que relacionaré, así, sociedad, política, ética y estética para ver cómo se manifiestan en conjunto en pantalla.

Por eso, para hablar de la metodología que utilizaré a lo largo de toda mi tesis doctoral, iré por partes, ya que no solo será una, sino varias, que se ayudarán y complementarán entre sí. Primero (y por orden cronológico) llevaré a cabo un análisis literario de algunas de las obras utópicas y distópicas más significativas, algunas de las cuales ya he mencionado: Utopía, Ciudad del Sol o Nueva Atlántida, por una parte, y Un mundo feliz, 1984 o Fahrenheit 451, por otra, para ver qué pueden decirnos y cómo se relacionan entre ellas. Asimismo, echaré mano de textos como Principios de análisis literario, de Cesare Segre (1985); Estructura del texto artístico, de Yuri M. Lotman (1988); Teoría de la novela. Antología de textos del 
siglo Xx, de Enric Sullà (1996); Manual de crítica literaria contemporánea, de Fernando Gómez Redondo (2008), Conceptos de crítica literaria, de René Wellek (1968); Literatura comparada: principios y métodos, de María José Vega y Neus Carbonell (1998), o Historia social de la literatura y el arte, de Arnlod Hauser (1978; 1993a; 1993b) entre muchos otros. Todo este análisis literario irá acompañado de un análisis histórico. Así pues, también estudiaré, además de los conceptos utopía y distopía, los de modernidad y posmodernidad como referentes históricos en los que aparecen tanto la utopía como la distopía como género literario. Para esto me ayudaré de algunas obras como ¿Qué es Modernidad?, de Bolivar Echeverría (2009); Todo lo sólido se desvanece en el aire. La experiencia de la modernidad, de Marshall Berman (1989); Modernidad y posmodernidad, de Armando Roa (1995); El debate modernidad-posmodernidad, de Nicolás Casullo (2004); Los orígenes de la posmodernidad, de Perry Anderson (2000); La posmodernidad, de Hal Foster (2008); Posmodernidad, de Esther Díaz (1999); La condición de la posmodernidad: investigación sobre los orígenes del cambio cultural, de David Harvey (1998); De la mano de Alicia: Io social y lo político en la postmodernidad, de Boaventura de Sousa Santos (1998), o Las ilusiones del posmodernismo, de Terry Eagleton (1997), entre otras.

Además, analizaré aspectos sociopolíticos, éticos y estéticos tanto de películas como de series de televisión distópicas. Parte del material que he utilizado para ello está compuesto de libros como Manual básico de lenguaje y narrativa audiovisual, de Federico Fernández Díez y José Martínez Abadía (1999), para aprehender las reglas básicas del mundo audiovisual; Estética del cine. Espacio filmico, montaje, narración, lenguaje, de Jacques Aumont et al. (2008), para entender todos los elementos observables en una película o serie de televisión, o Hacia una filosofía de la fotografía, de Vilém Flusser (1990) que toma la imagen como algo susceptible de interpretación. Así como De la literatura al cine. Teoría y análisis de la adaptación, de José Luis Sánchez Noriega (2000); Leer el cine. La teoría literaria en la teoría cinematográfica, de José Antonio Pérez Bowie (2008); Las cinco claves del cine, de Joseph Mascalli (1990); ¿Qué es una buena película?, de Laurent Jullier (2006); Nuevos conceptos de la teoría del cine. Estructuralismo, semiótica, narratología, psicoanálisis, intertextualidad, de Robert Stam et al. (1999); Sociología del cine. La apertura para la historia de mañana, de Pierre Sorlin (1985), o Veinte lecciones sobre la imagen y el sentido, de Guy Gauthier (1996).

En cuanto a la metodología en sí, para el análisis del material audiovisual me ayudaré (no de todos los elementos, sino tan solo de los que considere necesarios) de una aproximación desde múltiples perspectivas, combinando el análisis cuantitativo y cualitativo que 
expone Laura Cortés-Selva en su artículo «Fotografía y series de televisión. Metodología para el análisis del estilo visual televisivo» (2016: 135-150). Este análisis, en resumen, se divide en tres niveles: en primer lugar, descriptivo (descripción del estilo visual con un análisis del plano individual) en el que se observarán, entre otras, variables formales (la duración del plano en segundos, la escala de plano, la tipología de movimientos de cámara, el diseño lumínico y el diseño colorimétrico), variables de contenido (las localizaciones dominantes, los espacios interiores o exteriores) y variables temporales (si es de día o de noche o si es presente, pasado o futuro), mediante una metodología cuantitativa (descriptiva, susceptible de medición). En segundo lugar, un nivel analítico en el que se analizarán el tiempo y el movimiento, es decir, la escena y la secuencia, para encontrar significados y posibles funciones que cumplen los patrones estilísticos hallados mediante una metodología cualitativa (o interpretativa). Y en tercer lugar, el histórico, que se encaja en el contexto de su tiempo y que tiene en cuenta las condiciones económicas, tecnológicas, los estándares de la industria y ciertos códigos estético-culturales de un determinado momento histórico, ya que se entiende que el estilo es el resultado de una conjunción de todo ello.

Finalmente, introduciré la perspectiva de género en el análisis. En la distopía existe, implícitamente y explícitamente, el elemento de las relaciones de poder, que pueden interpretarse en clave de género (Turbet, 2003: 14). Además, la perspectiva de género nos des-vela que hay ciertos términos que son construidos (Laqueur, 1994: 2125), que hay productos que son sociales y culturales (Ortner y Whitehead, 1981: 1) y es exactamente adonde quiero llegar: cómo se muestra en las series de televisión esa construcción social y cultural que es el género, ya que estas han alcanzado en los últimos años una relevancia cultural y social enorme (Muñoz Fernández, 2016: 70). Además, la idea es analizar cómo se muestran las relaciones de género en las series escogidas y cómo rompen o los modelos y estereotipos de género que nos han querido vender como naturales pero que, en realidad, son construcciones históricas al servicio de intereses políticos y sociales (Butler, 1990: 39-40). Así pues, con el visionado de estas series de televisión no solo me centraré en el análisis de los modelos y estereotipos de género que arrastramos sino que, además, en si estas contribuyen a perpetuar dichos modelos y estereotipos o si, por el contrario, nos ayudan a romperlos, y, si es así, cómo.

\section{Estructura y planificación}

Para acabar con la exposición de mi proyecto, explicaré brevemente la estructura y la planificación de mi tesis doctoral. Con 
la finalidad de abordar el objetivo general y los objetivos específicos a través de la metodología propuesta, el orden lógico de mi tesis será el siguiente: en la primera parte, a modo de presentación, trataré, desde la literatura, la historia y lo audiovisual la idea de utopía y de distopía. En la segunda parte, la más personal de este trabajo, y que sigue desde la primera, tratará de profundizar filosóficamente en el concepto de distopía a partir del análisis y la reflexión del lenguaje y la narrativa audiovisual que nos muestran algunas series de televisión en la actualidad.

En cuanto a la planificación, la tesis doctoral está planteada para desarrollarla, a tiempo completo, durante tres años. Dado que la propuesta esbozada tiene una lógica interna que no escapa a sus partes y no está planteada desde apartados independientes, sino a partir de apartados que se apoyan y completan, no se podrá plantear una planificación cerrada, iré tratando los distintos temas a lo largo de estos tres años. Si se trata de ser lo más ajustado posible, podría anticipar que el primer año estará dedicado a la revisión bibliográfica, lectura y revisión de los conceptos de utopía y distopía en general, además de la investigación de las obras escritas y películas realizadas de temática utópica y distópica más significativas de la historia. Así, el segundo año arrancará con una revisión filmográfica y el visionado a fondo de las películas de temática distópica; en este punto introduciré la metodología propuesta propuesta para el análisis audiovisual (sociopolítico, ético y estético). Así pues, podré profundizar en todas esas películas para extraer tanto su sentido ético como estético y lanzarme a la interpretación. Y con todo, a partir del tercer año, visionaré las series seleccionadas para tener una sólida base en cuanto a novelas (textos literarios), películas (material audiovisual) utópicas y distópicas por una parte y haber desarrollado la metodología propuesta y seguirla a lo largo del trabajo, por otra. De esta manera, empezaré a trabajar en detalle las series de televisión. Para terminar, dedicaré los últimos meses a leer, revisar, corregir y acabar de definir y dar forma a toda la tesis doctoral en conjunto.

\section{Bibliografía}

Aldridge, Alexandra. 1984. The Sceintific World View in Dystopia. Michigan: UMI Research Press.

Anderson, Perry. 2000. Los orígenes de la posmodernidad. Barcelona: Anagrama.

Aumont, Jacques, Alain Bergala, Michel Marie y Marc Vernet. 2008. Estética del cine. Espacio fílmico, montaje, narración, lenguaje. Buenos Aires: Paidós. 
Berman, Marshall. 1989. Todo lo sólido se desvanece en el aire. La experiencia de la modernidad. Buenos Aires: Siglo XXI.

Blanco Martínez, Rogelio. 1999. La ciudad ausente. Utopía y utopismo en el pensamiento occidental. Madrid: Akal.

Buber, Martin. 1955. Caminos de Utopía. Ciudad de México: Fondo de Cultura Económica.

Butler, Judith. 1990. El género en disputa. El feminismo y la subversión de la identidad. Ciudad de México: Paidós.

Cappelletti, Ángel J. 1966. Utopías: antiguas y modernas. Quito: J. M. Cajica.

Casullo, Nicolás, ed. 2004. El debate modernidad-posmodernidad. Buenos Aires: Retórica.

Cortés-Selva, Laura. 2016. "Fotografía y series de televisión. Metodología para el análisis del estilo visual televisivo». index.comunicación. Revista científica en el ámbito de la Comunicación Aplicada 6 (2): 135-150.

Costa Vila, Jordi. 2014. "El tiempo de la distopía». El País, 10 de octubre.

https://elpais.com/cultura/2014/10/01/babelia/1412173689_53 9421.html

Díaz, Esther. 1999. Posmodernidad. Buenos Aires: Biblos.

Duveau, Georges. 1961. Sociologie de l'utopie es autres «essais». París: Presses Universitaires de France.

Eagleton, Terry. 1997. Las ilusiones del posmodernismo. Buenos Aires: Paidós.

Echeverría, Bolivar. 2009. ¿Qué es Modernidad?. Ciudad de México: Universidad Nacional Autónoma de México.

Fernández Díez, Federico y José Martínez Abadía. 1999. Manual básico de lenguaje y narrativa audiovisual. Barcelona: Paidós.

Flusser, Vilém. 1990. Estética del cine. Espacio fílmico, montaje, narración, lenguaje. Ciudad de México: Trillas.

Foster, Hal, ed. 2008. La posmodernidad. Barcelona: Kairós.

Gauthier, Guy. 1996. Veinte lecciones sobre la imagen y el sentido. Madrid: Cátedra.

Gómez Redondo, Fernando. 2008. Manual de crítica literaria contemporánea. Madrid: Castalia

Harvey, David. 1998. La condición de la posmodernidad: Investigación sobre los orígenes del cambio cultural. Buenos Aires: Amorrortu. 
Hauser, Arnold. 1978. Historia social de la literatura y el arte 1. Madrid: Labor.

-. 1993a. Historia social de la literatura y el arte 2. Madrid: Labor.

-. 1993b. Historia social de la literatura y el arte 3. Madrid: Labor.

Jullier, Laurent. 2006. ¿Qué es una buena película? Barcelona: Paidós.

Laqueur, Thomas. 1994. La construcción del sexo. Cuerpo y género desde los griegos hasta Freud. Madrid: Cátedra.

Lotman, Yuri M. 1988. Estructura del texto artístico. Madrid: Istmo.

Mascalli, Joseph. 1990. Las cinco claves del cine. Buenos Aires: Sindicato de la Industria Cinematográfica Argentina.

Morán Bueno, David. 2014. «Literatura distópica: cuando el futuro es una pesadilla». $A B C, 5$ de octubre.

https://www.abc.es/cultura/libros/20140805/abci-literaturadistopica-201408041809.html

Mumford, Lewis. 2013. Historia de las utopías. Logroño: Pepitas de calabaza.

Muñoz Fernández, Horacio. 2016. "¿Son arte las series de televisión?». index.comunicación. Revista científica en el ámbito de la Comunicación Aplicada 6 (2): 69-82.

Núñez Ladevéze, Luis. 1986. "Sobre el proceso de la utopía a la distopía». Revista de Estudios Políticos 52: 111-123.

Ortner, Sherry B. y Harriet Whitehead. 1981. "Introduction: Accounting for Sexual Meanings». En Sexual Meanings: The Cultural Construction of Gender and Sexuality, editado por Sherry B. Ortner y Harriet Whitehead, 1-28. Cambridge: Cambridge University Press.

Pérez Bowie, José Antonio. 2008. Leer el cine. La teoría literaria en la teoría cinematográfica. Salamanca: Ediciones Universidad de Salamanca.

RAE. 2014. Diccionario de la Lengua Española. 23ạ edición. Barcelona: Espasa.

Roa, Armando. 1995. Modernidad y posmodernidad. Santiago de Chile: Andrés Bello.

Sánchez Noriega, José Luis. 2000. De la literatura al cine. Teoría y análisis de la adaptación. Barcelona: Paidós.

Segre, Cesare. 1985. Principios de análisis del texto literario. Barcelona: Crítica.

Servier, Jean. 1969. Historia de la utopía. Caracas: Monte Ávila. 
Sorlin, Pierre. 1985. Sociología del cine. La apertura para la historia de mañana. Ciudad de México: Fondo de Cultura Económica.

de Sousa Santos, Boaventura. 1998. De la mano de Alicia: lo social y lo político en la postmodernidad. Bogotá: Siglo del Hombre, Facultad de Derecho de la Universidad de los Andes y Uniandes.

Stam, Robert, Robert Burgoyne y Sandy Flitterman-Lewis. 1999. Nuevos conceptos de la teoría del cine. Estructuralismo, semiótica, narratología, psicoanálisis, intertextualidad. Barcelona: Paidós.

Sullà, Enric. 1996. Teoría de la novela. Antología de textos del siglo $x x$. Barcelona: Crítica.

Trousson, Raymond. 2011. «Tomás Moro, padre de la utopía moderna». En Utopía, Tomás Moro, 9-25. Madrid: Círculo de Bellas Artes.

Turbet, Silvia. 2003. "La crisis del concepto de género». En Del sexo al género. Los equívocos de un concepto, editado por Silvia Turbet, 7-38. Madrid: Cátedra.

Vega, María José y Neus Carbonell. 1998. La literatura comparada: principios y métodos. Madrid: Gredos.

Wellek, René. 1968. Conceptos de crítica literaria. Caracas: Ediciones de la Biblioteca de la Universidad Central de Venezuela. 